\title{
MODELING INFORMATION FLOW IN THE SUPPLY CHAIN OF STRUCTURAL STEEL COMPONENTS
}

\author{
Emre Caner AKCAYa, Semiha ERGAN ${ }^{\mathrm{b}}$, David ARDITI ${ }^{\mathrm{a}}$ \\ ${ }^{a}$ Department of Civil, Architectural and Environmental Engineering, Illinois Institute of Technology, \\ Alumni Memorial Hall, 3201 S. Dearborn St., 60616, Chicago, USA \\ ${ }^{b}$ Department of Civil and Urban Engineering, NYU Tandon School of Engineering, Six Metro Tech Center, \\ Brooklyn, 11201, New York, USA
}

Received 09 Sep 2016; accepted 27 Oct 2016

\begin{abstract}
Accessing the required information in the supply chain of structural steel components is critical for minimizing costly reworks and delays. This paper identifies the information items generated in the different phases of the supply chain related to structural steel components and formalizes the process of producing and using this information. Precise details about different features of the components (e.g., their geometry and weight, connection details, cutting/bending/ punching requirements, and the type and grade of the material) are set in the various tasks performed in the different phases of the supply chain. Regardless of whether one uses paper-based systems or advanced technologies such as smart tags and radio-frequency identification (RFID), a better understanding is achieved of the processes through which a structural steel component passes. The results of this research can be used to streamline the information flow in the supply chain of structural steel components, regardless of the type of tracking technology used, hence reducing delays and reworks.
\end{abstract}

Keywords: supply chain management, structural steel components, information flow model, construction, technology, RFID.

\section{Introduction}

A variety of information items about building components need to be generated by, and transferred between designers, fabricators, and contractors in the various phases of the supply chain such as procurement, shipment, and erection. Accessing and exchanging component-specific information is important in streamlining the information flow between parties and in reducing costly reworks and delays (Ergen, Akinci 2008). For structural steel components that are fabricated off-site and shipped to job sites, access to and exchange of information becomes even more critical as structural steel components are costly to reproduce in case of a rework. For a standard steel building project, it takes about 15 hours, on average, to produce a ton of fabricated components (which corresponds to $18.6 \mathrm{~m}^{2}$ of a steel building's area); fabrication costs are variable with materials constituting $30-35 \%$ of the fabrication cost (AISC 2016). Given that a large highrise steel building requires tens of thousands of tons of steel, the rework associated with these components could be quite high (AISC 2016).

A structural steel component consists of either single members such as profiles and plates that have been punched or bent according to specifications, or assemblies that have been fabricated using profiles and plates. During fabrication, shipment, and erection, various questions about components must be answered in a timely manner. Examples of such questions include: "where is a component of interest with respect to the supply chain?", "what are the connecting components to an assembly of interest?", and "in which truck will a component of interest be delivered?". In current practice, information about structural steel components is generally exchanged on paper-based documents, such as a cutting sheet attached to a component during fabrication or a delivery invoice during shipment or at the erection stage. This practice is not efficient, as these documents can potentially get lost while components are being transferred from one location to another. It is not easy to access and exchange information in a paper-based approach. Consequently, it is difficult to see at what phase of the supply chain these information items are generated, and at what phases (and in which specific tasks) these information items are used/modified as components move in the supply chain. Modifications made to components during the preceding

Corresponding author: Emre Caner Akcay

E-mail: eakcay@iit.edu 
phases are either not recorded or are stored on different documents, which also make it difficult to locate and access the information in succeeding phases. Hence, various location identification technologies have been used that can provide component information efficiently whenever needed, and that can streamline the information flow accessed by and exchanged between parties during the life cycle of a component. To implement such technologies for structural steel components, an essential first step is to identify what information is generated and shared as structural steel components move in the supply chain, and to identify the tasks in the supply chain that necessitate generation of such information. Therefore, the research questions are: "What are the information items generated in the different phases of the supply chain related to structural steel components?" and "How is the information flow set up within and between the phases of the supply chain?". For this purpose, a process model is proposed in this paper to manage the flow of structural steel components through the supply chain, from design to erection.

Although all engineered-to-order components (such as escalators, elevators, Heating, Ventilation and Air-Conditioning (HVAC) systems, precast concrete components, and structural steel components) go through the generic phases of the supply chain such as design, fabrication, shipment, and erection/assembly, this research takes a step further to detail the processes in each of these phases for structural steel components and to define the information items that are generated and exchanged throughout the processes. While all engineered-to-order components go through the generic phases of the supply chain, the processes largely depend on the type of engineered-toorder component (e.g., escalator, HVAC, concrete components, steel components). The processes that are typical to structural steel components (such as using plates and profiles, cutting, bending, punching, drilling, riveting, welding, etc.) are unique when compared to the processes typical to precast concrete components (such as preparing molds, placing reinforcements, mixing concrete, pouring concrete, vibrating, curing, testing concrete, etc.) and cer-

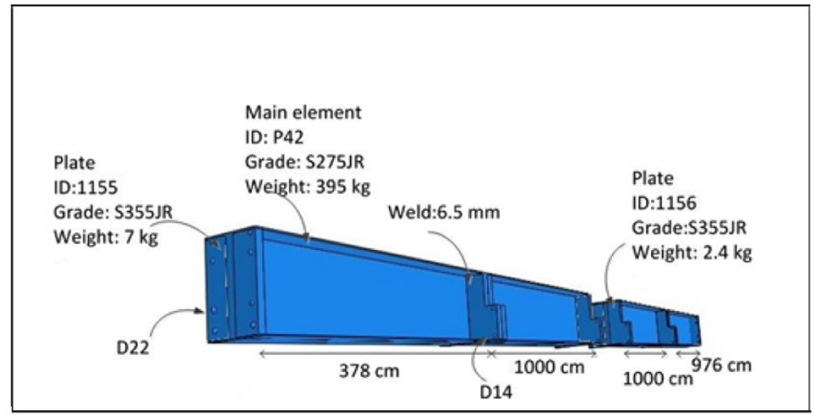

Fig. 1. A 3D view of an example assembly (A/216)

tainly much different when compared to mechanical systems. Recognizing these processes in the supply chain of structural steel components along with the information needed to perform these processes adequately would be most welcome for practitioners in the steel construction field. This research is performed in response to this need and is unique. Its objective is to investigate the information flow in the supply chain of structural steel components by identifying the information items in each phase of the supply chain and providing an analysis of when and where information is generated and used.

\section{Assembly fabrication process}

A structural steel assembly is composed of several individual members that are bolted or welded together. If one traces a structural steel component in the design, fabrication, shipment, and erection phases, one can observe that information items generated in early phases of the supply chain are used frequently in downstream phases. For example, in the manufacturing plant, various design-related information items are needed in order to cut, bend, and weld the raw steel materials into assemblies such as the one seen in Figure 1, with an assembly identification number of "A/216".

The information items created and used in the various phases of the supply chain are provided in Table 1. This table shows that the information items are often

Table 1. Examples of information items generated in relation to assembly A/216

\begin{tabular}{l|l}
\hline \multicolumn{1}{c|}{ Information item } & \multicolumn{1}{c}{ Flow through phases in supply chain } \\
\hline $\begin{array}{l}\text { Dimensions and cross section of the assembly } \\
\text { IDs of singles that form the assembly, thickness of plates } \\
\text { Storage location of fabricated components }\end{array}$ & $\begin{array}{l}\text { Design } \rightarrow \text { Fabrication } \rightarrow \text { Shipment } \rightarrow \text { Erection } \\
\text { Design } \rightarrow \text { Fabrication } \\
\text { Fabrication } \\
\text { Delding thickness, connecting bolt types, numbers, and sizes } \rightarrow \text { Fabrication } \rightarrow \text { Shipment } \rightarrow \text { Erection }\end{array}$ \\
Assembly ID (A/216) & $\begin{array}{l}\text { Design } \rightarrow \text { Fabrication } \rightarrow \text { Shipment } \rightarrow \text { Erection } \\
\text { Fabrication } \rightarrow \text { Shipment } \rightarrow \text { Erection }\end{array}$ \\
Total weight of the assembly & Fabrication $\rightarrow$ Shipment \\
Storage location of the assembly & Shipment $\rightarrow$ Erection \\
Package ID that contains assembly A/216 & Shipment $\rightarrow$ Erection \\
Weight of the package containing assembly A/216 & Shipment $\rightarrow$ Erection \\
ID of the truck that ships A/216 &
\end{tabular}


referred to in the downstream phases of the supply chain. Information about connecting plates and profiles (such as the location of connecting plates/profiles, the shape and dimensions of the plates/profiles, the dimensions and shape of the resulting assembly) is specified in the design phase. This information is needed to make the connections by cutting, punching, and welding individual members. In the traditional system, workers get the related information from hard or digital copies of relevant drawings. Such manual searches result in unnecessary time spent to access information. If one considers a large project with hundreds (maybe thousands) of assemblies, the manual search process becomes very cumbersome. Technology can help to eliminate such inefficiency.

In addition to the information generated in the design and fabrication phases, new information is generated in the shipment phase to be used not only in the shipment phase but also in the erection phase. For example, information must be available about the size, weight, shape and identification (ID) number of the assemblies to locate them in the storage yard, and to develop package lists for shipping, including package IDs, the list of assemblies and connections in each package, on which truck each package is loaded, etc. Such information is needed when a truck reaches the job site. Making packages for shipment is a complex operation that may require timeconsuming visual searches to locate the assemblies in the storage yard and that may end up with packages that contain the wrong or missing assemblies.

Once the structural steel assemblies arrive at a job site, they are stored at a storage yard until the day they are needed for erection. At the job site, workers need to know where the assemblies are stored, their final erection location (e.g., on which floor, at which column/beam intersection), and connection details (e.g., the number of bolts, size and type of bolts, welding specifications). If a manual search is used to locate an assembly in the storage yard and access the related information, mistakes are inevitable, leading to inefficiencies such as lost assemblies and reworks.

To summarize, in steel building construction, assemblies are designed by design firms, put together by fabricators, sent to the construction site by shipping agencies, and erected on site by contractors. Each one of these participants generates information to be used not only by themselves but also by participants involved in downstream activities. The current manual system of accessing and exchanging this information is prone to mistakes, causing delays, costly reworks, and inefficiencies. These problems can be minimized if the four participants know the nature of the information that is to be generated at each phase of the supply chain and if this information is exchanged in an efficient way.

\section{Background research}

This research builds on and extends studies performed in relation to: (a) structural steel supply chains, (b) data standards for information exchange, and (c) representation and exchange of structural steel information in steel building construction.

\subsection{Research on structural steel supply chains}

Research in construction supply chains mostly emphasizes (a) the implementation of lean principles and techniques (e.g., Tommelein 2015; Pestana et al. 2014; Yin et al. 2014; Koskela et al. 2002; Tommelein, Weissenberger 1999), and (b) the application of information and tracking technologies (e.g., Park et al. 2016; Costin et al. 2014; Jiang et al. 2012; Wegelius-Lehtonen, Pahkala 1998; Ergen et al. 2007).

Research into lean principles and techniques indicates that construction supply chains are different than manufacturing supply chains. This research investigates on-site/ off-site manufacturing, the types of parties involved in the chain, inter-organizational relationships, and volumes of production (e.g., Aziz, Hafez 2013; Vrijhoef, Koskela 1999; Koskela 1992; Bertelsen 2004; O'Brien et al. 2002; Arbulu et al. 2003; Naim et al. 1999). Lean principles that are suggested for improving construction supply chains include just-in-time manufacturing, dependability and variability analysis (e.g., Tommelein et al. 1999), standardization of preassembly practices (e.g., Arbulu, Ballard 2004), bringing a systems perspective to the supply chain (e.g., Wang, Riley 2016; Bashford et al. 2003; Wegelius-Lehtonen, Pakkala 1998), and flow modeling (e.g., Tommelein et al. 1999). These studies provide an understanding of the bottlenecks in construction supply chains, and of the factors that affect the flow of materials and components through the supply chain. The research presented in this work builds on this foundation and focuses on the identification of the information that should be flowing along with the components in the supply chain for structural steel components. There is only a limited number of studies that focus on the supply chain of structural steel components (e.g., Tommelein, Weissenberger 1999; Furlani, Pfeffer 2000). The need persists to identify the information that is critical to tracking structural steel components and to improving the process in the supply chain.

Research into the utilization of information technology (IT) and tracking technologies in improving construction supply chains, include information systems that capture the status of the order and information about components (e.g., Omar, Ballal 2009; Jang, Skibniewski 2008; Lin, Tserng 2001), and tracking technologies to identify the location of components (e.g., Park et al. 2016; Ergen et al. 2007; Wang et al. 2007; Shin et al. 2011; Furlani, Pfeffer 2000). Using empirical approaches, these studies demonstrate tangible improvements over traditional supply chain management practices in terms of time and money. Some of these studies identified what information to track for different types of components, such as precast concrete members, but not structural steel components. These studies are complementary in 
nature to the research presented in this paper in terms of flow modeling, but the information that is needed to track structural steel components needs to be identified. Hence, the research presented in this paper focuses on the identification of information needs for the structural steel supply chain.

\subsection{Research on data standards for information exchange}

The architecture/engineering/construction and facility management (AEC/FM) domain is rich in terms of data standards and parametric modeling systems. Among these, the data standards that are specific to structural steel include industry foundation classes (IFCs) and CIMSteel Integration Standards (CIS/2). These two major data standards help with the exchange of structural steel component information between parties throughout the supply chain. CIS $/ 2$ is an aspect model that is aimed at exchanging structural steel project information for all the parties involved in the supply chain (Eastman 1999) whereas IFCs target all phases of a construction project to support information needs for all parties involved, hence are more generic in scope (BuildingSmart 2015). With $\mathrm{CIS} / 2$, it is possible to exchange information about (a) analysis results such as nodes, element connectivity, section profiles, loads, material properties, forces and displacements; (b) a detailed design model, which incorporates physical representation with materials all the way to stairs, decking, and clip angles; and (c) a detailed model with fabrication information about bolts, welds and holes, their locations with respect to parts/assemblies, assembly information (what parts belong to what main member, location relative to the assembly, and location of assemblies in a global coordinate system) (Lipman 2009).

Though IFC does not focus on structural steel members specifically, it is capable of representing geometric, material and connection-specific information explicitly. For example, for a T beam, IFC is capable of representing all information associated with that beam using ifcBeam.

The data standards and delivery manuals can be leveraged to identify information items about structural steel components. However, these standards and manuals do not necessarily show in what phases of the supply chain these information items are generated. The study presented in this paper provides an overview of where each information item is generated in the supply chain, and which information is referred to in the subsequent phases, so that it will be possible to track the information to its origin, hence eliminating bottlenecks in the information flow process.

\subsection{Research on information flow and modeling approaches}

Various researchers have studied the information flow and process modeling of supply chains of different types of components such as pipe supports, precast concrete members, mechanical, electrical and plumbing components (e.g., Zheng et al. 2015; Arbulu, Tommelein 2002; Cheng et al. 2010; Ergen, Akinci 2008; Sacks et al. 2002). For example, Ergen and Akinci (2008) created an information flow for precast concrete components. By setting up four different information flow matrices, one for each phase of the supply chain (i.e., design, fabrication, shipment, and erection). They categorized the information items into design information, material information, component quality control (QC) reports, and coordination information. On the other hand, Arbulu and Tommelein (2002) showed five possible supply chain configurations for pipe supports used in power plants. Although they illustrated the process models for each configuration of pipe supports, they did not present the information items. These studies focus on pinpointing inefficiencies in the supply chains by developing detailed models of the processes (e.g., Arbulu, Tommelein 2002) and identifying information that flows with the components, as components move in the supply chain (e.g., Zheng et al. 2015; Ergen, Akinci 2008; Sacks et al. 2002). The research presented in this paper is complementary to these research studies in terms of process model development. However, it differs from the existing studies in that it studies the supply chain of structural steel components.

In addition to the research studies that focus on information flow modeling in AEC/FM supply chains, some research studies propose process/workflow modeling and data flow modeling techniques and approaches. Process modeling approaches are of various types, and are mainly developed for business process modeling. For example, The Action Port Model workflow enables the capturing of work processes using actions/tasks (as input, process, output) including time (e.g., absolute time, delays), resources (e.g., actors, tools, objects), external actors (e.g., people, systems), various flow types (e.g., triggering, terminating, singular) and conditions (e.g., a statement to be checked as true or false) (Trætteberg 1999; Carlsen 1998). Similar content is captured by various other workflow models such as Trigger models (Joosten 1994), State charts (Schumann, Michael 2009), FlowMake (Sadiq, Orlofka 1999), Action workflow (Medina-mora et al. 1992) and UML (Wirtz et al. 2000). The majority of these modeling approaches are task specific, but have limited capabilities in terms of information representation. The modeling tools that are specific to representing information flow processes include $\mathrm{C}-\mathrm{Wf}$ models that are capable of capturing information in a domain and mapping this information to processes (Bastos, Ruiz 2001), data flow diagrams that are capable of showing the flow of data in an information system (Ambler 2004), design structure matrices that show the information generated in processes leading to its use in a given set of processes (Browning 2001), and unified modeling language (UML) that has a wide variety of standard modeling tools that can be integrated to represent process and information models (Hruby 1998a, 1998b; Wirtz et al. 2000). In this research project, a UML based process modeling tool is used to show the dependencies between activities. 


\section{Methodology of the study}

In order to identify the information about structural steel components that is accessed by and exchanged between various parties, first of all, the process and the information flow within this process need to be identified. A process model is roughly the anticipation of what the process will look like (Rolland, Pernici 1998). Here, the process model incorporates the stages that a structural steel component passes through from design to erection. In order to identify the process and the information that is generated at each phase and that is accessed and exchanged in each subsequent phase, three different companies were contacted (see Table 2). Company A was an engineering design and fabrication firm, specializing in the design of heavy steel structures used in airports, bridges, commercial buildings and industrial plants. Company B was also an engineering design and fabrication firm, but specializing in the design of energy structures such as energy transmission lines, energy distribution networks and power distribution centers. Company $\mathrm{C}$ specialized in light weight steel fabrication for warehouses and housing units. All three companies were directly involved in the shipping of the components, and worked closely with contractors in the erection phase. As can be seen in Table 2, the company specializations, as well as the types of components being designed and fabricated, were different. This variety helped in constructing a generic process and information flow that can also be generalized for other companies working in the same field.

Three different methods were used to access and extract information from the said companies. The research methods included face-to-face interviews, ethnographic observations, and examination of frequently used documents. A summary of these research methods is provided below.

Face to face interviews: A face-to-face interview is a qualitative research method that involves in person interaction with a participant through a semi structured questionnaire (Opdenakker 2006). This method was selected because it eliminates misunderstandings and misinterpretations of the questions posed. Face to face interviews were conducted with site managers, site engineers, engineers, foremen and workers throughout the design, fabrication, shipment, and erection phases:

- In the design phase, nine design engineers were interviewed. They were asked what information items best characterize their tasks, and what information they generate for structural steel assemblies.

- In the fabrication phase, three foremen and twelve workers were interviewed. They were asked what information they expect to receive from design engineers when they procure structural steel assemblies and what additional information they generate in the fabrication phase that is to be used in upcoming phases.

- In the shipment phase, two foremen and three workers were interviewed. They were asked how they locate structural steel assemblies on the storage yard of the fabricator, what information they expect to receive from design engineers and fabricators, and what additional information they generate for use in the erection phase.

- In the erection phase, two site engineers, three foremen and fifteen workers were interviewed. They were asked how they locate components stored on the construction site, what information they expect from design engineers, fabricators, and shippers, and what additional information they generate for use by the inspection team and facility managers.

Ethnographic observations: This method is an important part of qualitative research, allowing researchers to closely observe and study a particular culture or group in order to better understand the customs, social structure and habits of the people (Richards 2010). This method was used to closely observe and study the works performed during the design, fabrication, shipment and erection of structural steel assemblies in order to define the tasks that are necessary to put together a structural steel assembly, as well as the information generated and used in these tasks.

Examination of project documents generated: In this research method, the contents of the documents issued in the different phases of the supply chain were analyzed. These documents included assembly lists, drawings, fabrication details, packaging and shipment documentation, and on-site paperwork.

\section{Proposed information flow model}

A detailed process model is presented in Figure 2, in which structural steel components go through the design, fabrication, shipment, and erection phases of the supply chain. This figure expressed in a UML (Unified Modeling Language) activity diagram provides a stand-

Table 2. General profile of the companies that participated in the study

\begin{tabular}{ccccc}
\hline Company & $\begin{array}{c}\text { Production capacity } \\
\text { (tons/yr) }\end{array}$ & $\begin{array}{c}\text { Experience } \\
\text { (years) }\end{array}$ & $\begin{array}{c}\text { Specialization in } \\
\text { Steel Structures }\end{array}$ & \multicolumn{1}{c}{$\begin{array}{c}\text { Typical types of structural } \\
\text { steel components produced }\end{array}$} \\
\hline Company A & 21600 & 22 & Heavy weight & $\begin{array}{l}\text { U profiles, L profiles, I profiles, IPBV sections, } \\
\text { IPE sections, truss members }\end{array}$ \\
Company B & 90000 & 55 & Heavy and light weight & $\begin{array}{l}\text { Energy towers, energy transmission lines, truss } \\
\text { members }\end{array}$ \\
Company $C$ & 30000 & 21 & Light weight & U profiles, L profiles, I profiles, truss members \\
\hline
\end{tabular}




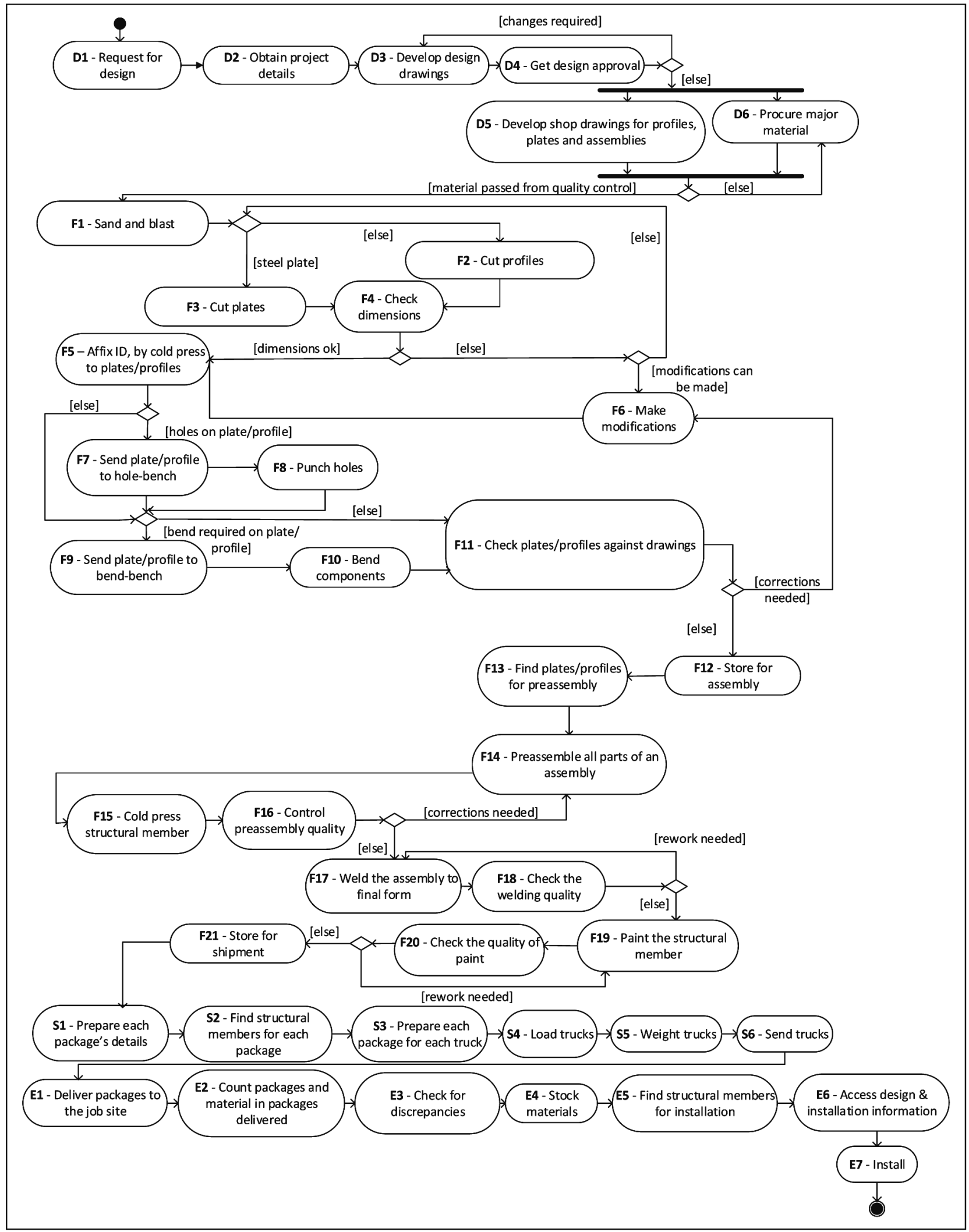

Fig. 2. UML activity diagram of process model for design, fabrication, shipment, and erection of structural steel members 
ard way of showing the flow of tasks within a process. A UML diagram was utilized in this study as a way to show the supply chain process for structural steel components. In this diagram, each task is given an ID composed of a letter that identifies the phase (D for design, $\mathrm{F}$ for fabrication, $\mathrm{S}$ for shipment, and $\mathrm{E}$ for erection) and a number that denotes the order in the process. For example, task F4 represents "check dimensions", the fourth task in the fabrication phase. The information generated in each task and used in subsequent tasks is shown in Table 3 with references to tasks in the process model with task IDs.

The design phase starts with a request for a steel structure from an owner (task D1). Upon this request, the design firm obtains the information such as loads, soil conditions, location and wind information, etc. required for an initial feasibility analysis (task D2). After, the agreement between the design firm and the owner is signed, the detailed structural design and analyses are performed to determine dimensions, cross sections, and types of the structural component (task D3). Shop drawings are prepared for the fabrication of plates, profiles, and assemblies (task D5) when the design is approved by the owner (task D4). Most of the information items related to structural steel components are generated in the design phase.

The fabrication phase starts with sanding and blasting the raw materials before fabricating the structural steel components (task F1). Raw materials are cut into profiles or plates (tasks F2 and F3) and after passing from a quality control in terms of cut dimensions (task F4), they are given unique cold pressed plate/profile IDs (task F5). Next, if the component needs a hole, it is sent to a hole-bench (task F7) equipped with a punching machine (task F8). Otherwise, it is sent directly to the bend-bench (task F9) for bending (task F10) if the component has a bending requirement. The punched and/or bended structural steel components pass through another quality control to double check the location and size of the punching and bending (task F11). Once the components are good in terms of cutting, punching and bending, they are kept in storage until they are picked for pre-assembly (task F12). Pre-assembly starts by locating the profiles and plates kept in storage and bringing them for pre-assembly (tasks F13 and F14). During pre-assembly, workers center the profiles and plates according to the shop drawing of the assembly, tentatively weld the plates/profiles to main components and cold press ID numbers on the assembly (task F15). The quality control crew checks the pre-assemblies for their correctness before the final assembly (task F16). Checked and preassembled structural steel components are welded in to their final forms (task F17) and cleaned to remove excess weld. Final welds are also checked against the thickness and size stated in the design drawings (task F18). All checked assemblies are sent to the paint shop (task F19), pass through a paint quality control for required thickness (task F20), and are kept in storage until shipment day (task F21).
The shipment phase is the third phase that a structural steel component passes through in the supply chain. It starts with preparing packaging lists that show which structural steel components and associated connection members will be in a package (task S1). The assemblies that are stored in the yard are found and sent to the shipping area (task S2) for packaging. Each package is set up such that similar components (in terms of size and shape) are put together. Each package is also given a unique ID. Once all components in a package are found in the yard, the package is prepared and sealed (task S3). The packaged assemblies and other components are loaded on tractor-trailers (task S4). Each tractor-trailer is weighed in order to record the total weight of the material (task S5) before it is shipped to the job site (task S6). When the steel components arrive on a job site (E1), packages are counted (task E2) and components in each package are found by matching cold pressed numbers to the numbers listed on the delivery receipt. All components are checked for any apparent damage or discrepancies before being accepted (task E3). All delivered structural steel components are stored in a location on the construction site unless it a just-in-time system is in place (task E4). For final erection, the required structural steel components and connections are located in the storage yard (task E5) and by using the erection information in the drawings, they are erected in their final locations (tasks E6 and E7).

The information items generated and used in each task are listed separately in Table 3. This information is organized in terms of component type (plates/profiles, assemblies and packages). As shown in Table 3, the information generated and used can be grouped under identification (ID) information (to identify and locate a plate, profile or assembly in the supply chain); geometric information (such as dimensions, shapes, areas of plates, profiles or assemblies,); weight information (weight of each plate, profile or assembly to keep track of produced, shipped, and erected components); connection information (types, location and size of connections between plates/profiles and assemblies, and between assemblies); cutting/bending/punching information (any information required to cut, bend and punch plates, profiles and assemblies); and material information (any information related to material characteristics, such as steel grade and type). This categorization is quite different than the categorization set up by Ergen and Akinci (2008) for precast concrete components because of the special conditions in the supply chain of structural steel components.

The information generated in the design phase constitutes as much as $86 \%$ of the total information generated about the supply chain management process, and is used not only in the design phase but also in the subsequent three phases (i.e., fabrication, shipment, and erection). On the other hand, the information generated in the fabrication phase constitutes only $8 \%$ of the total, and is used in the subsequent two phases. (i.e., shipment and erection). Similarly, the information generated in the 


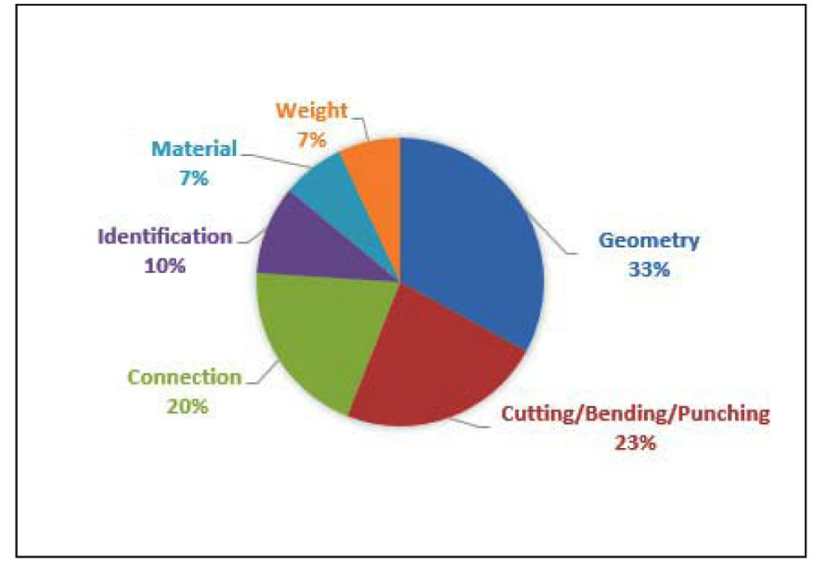

Fig. 3(a). Information generated in the design phase

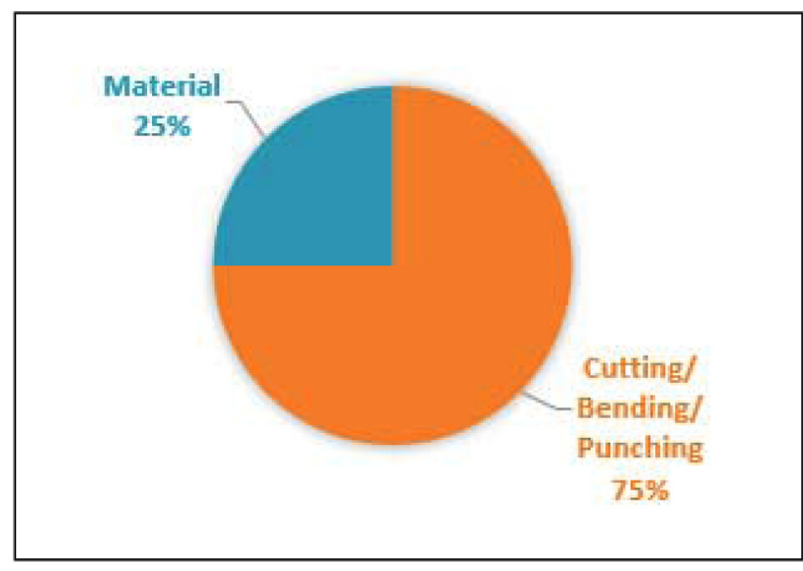

Fig. 3(b). Information generated in the fabrication phase

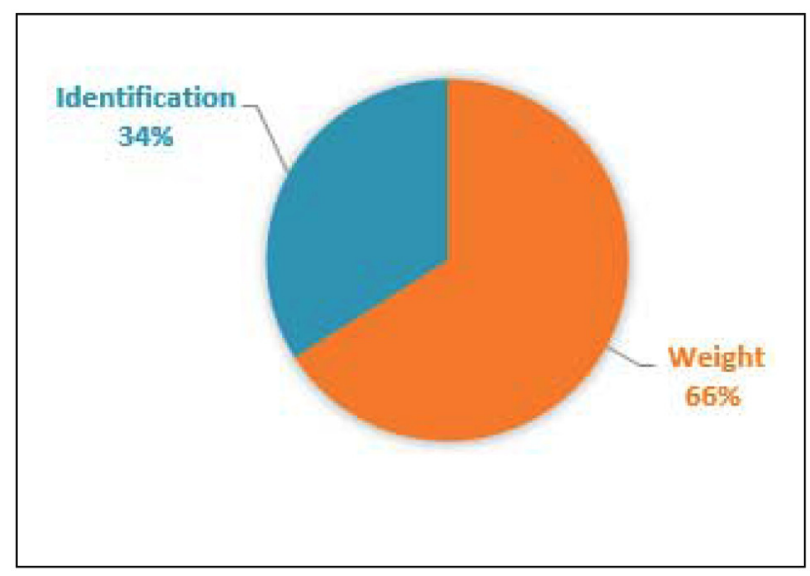

Fig. 3(c). Information generated in the shipment phase

shipment phase constitutes only $6 \%$ of the total, and is used in the last phase (i.e., erection). As seen in Figure $3 \mathrm{a}$, of the information generated in the design phase, most is either geometry-related (33\%) or cutting/bending/ punching-related (23\%). The information generated in the design phase is used in all the phases considered in this research, including fabrication, shipment, and erection.
According to Figure $3 b, 75 \%$ of the information generated during the fabrication phase is related to cutting/bending/punching, and $25 \%$ to the type and grade of the materials used. On the other hand, Figure $3 \mathrm{c}$ indicates that $66 \%$ of the information generated during the shipment phase is related to weight, a very important piece of information for trucks with limited capacities; only $34 \%$ of the information relates to identification. The information generated in the fabrication and shipment phases is used only in these phases.

It is observed that the information generated in the design phase is frequently used in the remaining phases and should be paid extra attention to in terms of correctness and accuracy. An approach that streamlines the flow of design-related information throughout the supply chain is expected to improve supply chain efficiency. One can see in Table 3 the phase in which an information is first generated, and whether it is used in other phases.

\section{Validation of the model}

The information flow model presented in this paper was used in field tests in five different projects that used RFID technology in the design, fabrication, shipping, and erection of various steel components in heavy steel structures (Akcay, Ergan 2013). The projects consisted of a highrise residential building of 40 floors, a stadium that could hold 30,000 spectators, an international airport terminal, a financial and trade center, and a shopping mall. The RFID system was used in all of the five projects as an experimental tool. Figure 4 shows a steel assembly with an RFID tag being unloaded in one of the construction sites. Five different types of projects undertaken for five different owners by five different designers and contractors were selected for the study in order to assess the effectiveness of the system in different environments.

The project manager of each project and a total of 14 designers, 21 foremen, 17 site engineers, and 36 workers were interviewed on the average three times each for periods ranging from half an hour to two hours, concerning supply chain activities in the design, fabrication, shipment, and erection phases. A semi-structured questionnaire survey was administered to the participants to elicit

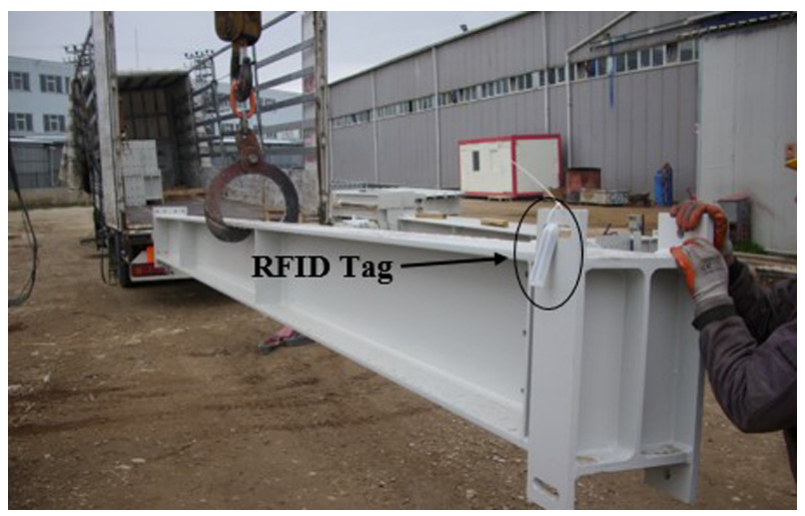

Fig. 4. Steel assembly with an RFID tag 
Table 3. Information items generated during design, fabrication, shipment, and erection of structural steel members

\begin{tabular}{|c|c|c|c|c|}
\hline $\begin{array}{l}\text { Component } \\
\text { type }\end{array}$ & $\begin{array}{l}\text { Category of } \\
\text { information }\end{array}$ & Generated information items & $\begin{array}{l}\text { Task in } \\
\text { which the } \\
\text { information } \\
\text { is generated }\end{array}$ & $\begin{array}{c}\text { Task in which the information is } \\
\text { used }\end{array}$ \\
\hline \multirow{16}{*}{$\begin{array}{l}\text { Plates and } \\
\text { profiles }\end{array}$} & Identification & ID (position number) of a plate/profile & D3 & F13, F14, S1 \\
\hline & \multirow{7}{*}{ Geometry } & Length or radius of a plate/profile & D3 & F3, F4, F6, F10, F11, F14 \\
\hline & & Width of a plate/profile & D3 & F3, F4, F6, F10, F11, F14 \\
\hline & & Height of a plate/profile & D3 & F3, F4, F6, F10, F11, F14 \\
\hline & & Type of plate or profile (e.g., L, C, U) & D3 & F3, F4, F6, F10, F11, F14 \\
\hline & & $\begin{array}{l}\text { Total number of plates having the same } \\
\text { geometry, shape and dimensions }\end{array}$ & D3 & F3, F4, F8, F10 \\
\hline & & Surface area of plate/profile & D3, D5 & $\mathrm{F} 2, \mathrm{~F} 3$ \\
\hline & & Geometric shape of plate/profile & D3 & F3, F4, F6, F10, F11, F14 \\
\hline & Weight & Weight of each plate/profile & D5 & F3, F5, F8, F12, F14, S1,S3,E7 \\
\hline & \multirow{5}{*}{$\begin{array}{l}\text { Cutting/ } \\
\text { Bending/ } \\
\text { Punching }\end{array}$} & $\begin{array}{l}\text { Offsets to the edges for cuts and bending } \\
\text { points for a plate/profile }\end{array}$ & D5 & F3, F8, F10 \\
\hline & & Total number of holes on a plate/profile & D5 & F6, F8, F11 \\
\hline & & Dimensions of holes on a plate/profile & D5 & F6, F8, F11 \\
\hline & & Locations of holes on a plate/profile & D5 & F6, F8, F11 \\
\hline & & Bending location & D5 & F6, F10, F11 \\
\hline & \multirow{2}{*}{$\begin{array}{l}\text { Type and } \\
\text { grade of } \\
\text { material }\end{array}$} & Type of material used for a plate/profile & D5 & F3, F5, F8 \\
\hline & & Grade of material used for a plate/profile & D5 & $\mathrm{F} 3, \mathrm{~F} 5, \mathrm{~F} 8$ \\
\hline \multirow{16}{*}{ Assemblies } & \multirow[t]{2}{*}{ Identification } & $\begin{array}{l}\text { Assembly number where each plate/profile } \\
\text { belongs to }\end{array}$ & D3 & F13, F14, F15 \\
\hline & & ID of each assembly & D3 & F14, F15, S1, S2, E5, E6, E7 \\
\hline & \multirow{3}{*}{ Geometry } & Length, width, height of an assembly & D3 & $\begin{array}{l}\text { F3, F4, F6, F10, F11, F14, S1, S2, } \\
\text { S3, E5 }\end{array}$ \\
\hline & & Total surface area of an assembly & D3, D5 & $\mathrm{F} 2, \mathrm{~F} 3$ \\
\hline & & $\begin{array}{l}\text { Geometric shape of an assembly, section } \\
\text { geometry }\end{array}$ & D3, D5 & $\begin{array}{l}\text { F3, F4, F6, F10, F11, F14, S1 S2, } \\
\text { S3, E5 }\end{array}$ \\
\hline & Weight & Total weight of an assembly & D5 & $\mathrm{F} 14, \mathrm{~S} 1, \mathrm{~S} 3, \mathrm{E} 7$ \\
\hline & \multirow{6}{*}{ Connection } & $\begin{array}{l}\text { Location }(\mathrm{x}, \mathrm{y}, \mathrm{z}) \text { of erection for each assem- } \\
\text { bly }\end{array}$ & D5 & E5, E6, E7 \\
\hline & & Welding thickness for each connection & D5 & E5, E6, E7 \\
\hline & & $\begin{array}{l}\text { IDs of assemblies that join through a con- } \\
\text { nection }\end{array}$ & D5 & E5, E6, E7 \\
\hline & & $\begin{array}{l}\text { Number of connecting bolts for a connec- } \\
\text { tion }\end{array}$ & D5 & S1, S2, S3, E5, E6, E7 \\
\hline & & Size of connecting bolts for a connection & D5 & $\mathrm{S} 1, \mathrm{~S} 2, \mathrm{~S} 3, \mathrm{E} 5, \mathrm{E} 6, \mathrm{E} 7$ \\
\hline & & Type of connecting bolts & D5 & S1, S2, S3, E5, E6, E7 \\
\hline & \multirow{3}{*}{$\begin{array}{l}\text { Cutting/ } \\
\text { Bending/ } \\
\text { Punching }\end{array}$} & $\begin{array}{l}\text { Machine to use for cutting, bending, punch- } \\
\text { ing? }\end{array}$ & D5, F2, F3 & F2, F3 \\
\hline & & $\begin{array}{l}\text { Cutting/bending/punching type (plain, pro- } \\
\text { grammed) }\end{array}$ & D5, F2, F3 & $\mathrm{F} 2, \mathrm{~F} 3$ \\
\hline & & $\begin{array}{l}\text { Number of components to process per ma- } \\
\text { chine? }\end{array}$ & F2, F3 & $\mathrm{F} 2, \mathrm{~F} 3$ \\
\hline & $\begin{array}{l}\text { Type and } \\
\text { grade of ma- } \\
\text { terial }\end{array}$ & Raw material category & $\mathrm{F} 2, \mathrm{~F} 3$ & $\mathrm{~F} 2, \mathrm{~F} 3$ \\
\hline \multirow[t]{3}{*}{ Packages } & Identification & $\begin{array}{l}\text { Number of assemblies and plates/profiles in } \\
\text { a package }\end{array}$ & S1 & S2, E2, E3, E5, E6, E7 \\
\hline & \multirow{2}{*}{ Weight } & Package weight & S1 & S3, S5 \\
\hline & & Number of components in a package & S1 & S3, S5, E2, E3 \\
\hline
\end{tabular}


information about the benefits of the RFID system and the information flow model used in the implementation.

The reactions from all the participants in the survey were favorable. They pointed out that compared to the traditional manual system, the RFID-based system had tangible advantages in terms of reduction in time to locate components, reduction of human errors, increased accuracy for accessing information about components, and ease of handling the many different components. The participants indicated that the information flow model presented in this paper and that was used to populate the RFID tags was considered to be one of the most important factors that contributed to the success of the system. Many of the advantages of the RFID system could not have been realized was it not for the information flow model that allowed the participants to have access to the right information in a timely fashion. In addition to these interviews, ethnographic observations were conducted. The feedback received from the participants interviewed indicates that the outcome of this research can be used to streamline the information flow in the supply chain of structural steel components, regardless of the type of tracking technology used, hence reducing delays and reworks.

\section{Conclusions}

This paper presents a typical information flow model of structural steel components through the four phases of a supply chain that include design, fabrication, shipment, and erection. The information items used in the model are generated and referred to in various phases of the supply chain. The primary contributions of this research include: (a) the formulation of an information flow process for heavy and light weight structural steel components (profiles, plates, and assemblies), a process that is extensively discussed in the literature for precast concrete components, but seldom for structural steel components; (b) the identification of information items generated and exchanged in the different phases of the supply chain, drawing attention to the work of the professionals generating the information in each phase; and (c) the analysis of the source and the destination of information from design to erection, highlighting the importance of efficiently exchanging information between phases.

The information generated and used in the supply chain of structural steel components is grouped for component type (plate/profile, assembly and packages) relative to: geometry, ID, weight, type and grade of the material, type of connection, and cutting/bending/punching information. Geometry and connection-related information dominates the supply chain of structural steel components.

The information generated during the design phase is used in the fabrication, shipping, and erection phases. The information generated in the fabrication phase is related mostly to cutting/bending/punching and to a lesser extent to the type and grade of the material used. The information generated in the shipment phase is related to weight and to the components' IDs, both important for packaging and trucking operations, as well as receiving operations at the construction site. This distribution shows that design-related information is used in all phases of the supply chain and should receive extra attention in terms of correctness and accuracy. The proposed approach to streamline the flow of design-related information throughout the supply chain is expected to improve the efficiency of the supply chain and reduce the document based access and control of design information. The feedback from the participants of five different projects and from the documents examined validated the usefulness of the information flow model and of the information items generated and used in the design, fabrication, shipment, and erection phases of the supply chain of structural steel components.

It should be noted that the information flow presented in this paper does not cover the post-erection phase. Further research could look into this phase. Also, the information flow presented in this paper could be expanded to cover specific types of steel construction such as industrial buildings and bridges.

\section{Disclosure statement}

Authors do not have any competing financial, professional, or personal interests from other parties.

\section{References}

AISC. 2016. The structural steel supply chain [online], [cited 10 January 2016]. American Institute of Steel Construction. Available from Internet:

http://www.aisc.org/content.aspx?id=3790

Akcay, E. C.; Ergan, S. 2013. Test results for locating structural steel assemblies and packages using RFID, in $30^{\text {th }}$ CIB W78 International Conference, 9-12 October 2013, Beijing, China.

Ambler, S. W. 2004. The object premier: Agile model driven development with UML 2. $3^{\text {th }}$ ed. Cambridge University Press. https://doi.org/10.1017/CBO9780511584077

Arbulu, R. J.; Tommelein, I. D. 2002. Alternative supply chain configurations for engineered or catalogued made-to-order components: Case study on pipe supports used in power plants, in $10^{\text {th }}$ Annual Conference on Lean Construction, 6-8 August 2002, Gramado, Brazil.

Arbulu, R. J.; Tommelein, I. D.; Walsh, K. D.; Hershauer, J. C. 2003. Value stream analysis of a re-engineered construction supply chain, Building Research \& Information 31(2): 161-171. https://doi.org/10.1080/09613210301993

Arbulu, R.; Ballard, G. 2004. Lean supply systems in construction, in 12th Annual Conference on Lean Construction, 3-5 August 2004, Elsinore, Denmark.

Aziz, R. F.; Hafez, S. M. 2013. Applying lean thinking in construction and performance improvement, Alexandria Engineering Journal 52(4): 679-695. https://doi.org/10.1016/j.aej.2013.04.008

Baldwin, A. N.; Austin, S. A.; Hassan, T. M.; Thorpe, A. 1999. Modeling information flow during the conceptual and schematic stages of building design, Construction Management and Economics 17: 155-167. https://doi.org/10.1080/014461999371655

Bashford, H. H.; Sawhney, A.; Walsh, K. D.; Kot, K. 2003. Implications of even flow production methodology for 
US housing industry, Journal of Construction Engineering and Management 129(3): 330-337.

https://doi.org/10.1061/(ASCE)0733-9364(2003)129:3(330)

Bastos, R. M.; Ruiz, D. D. A. 2001. Towards an approach to model business processes using workflow modeling techniques in production systems, in $34^{\text {th }}$ Annual Hawaii International Conference on System Sciences, 3-6 January 2001, Los Vaqueros, USA.

https://doi.org/10.1109/HICSS.2001.927231

Bertelsen, S. 2004. Lean construction: where are we and how to proceed, Lean Construction Journal 1(1): 46-69.

Browning, T. 2001. Applying the design structure matrix to system decomposition and integration problems: a review and new directions, IEEE Transactions on Engineering Management 48(3): 292-306. https://doi.org/10.1109/17.946528

BuildingSmart. 2015. Model: industry foundation classes-IFC [online], [cited 25 December 2015]. Available from Internet: http://buildingsmart.com/standards/ifc

Carlsen, S. 1998. Action port model: a mixed paradigm conceptual workflow modeling language, in $5^{\text {th }}$ International Conference on Cooperative Information Systems, 20-22 August 1998, New York, USA. https://doi.org/10.1109/coopis.1998.706274

Cheng, J.; Law, K.; Bjornsson, H.; Jones, A.; Sriram, R. 2010. Modeling and monitoring of construction supply chains, Advanced Engineering Informatics 24(4): 435-455. https://doi.org/10.1016/j.aei.2010.06.009

Costin, A.; Pradhananga, N.; Teizer, J. 2014. Passive RFID and BIM for real-time visualization and location tracking, in Construction Research Congress: Construction in a Global Network, 19-21 May 2014, Atlanta, USA.

Eastman, C. 1999. Building product models: computer environments, supporting design and construction. $1^{\text {st }}$ ed. CRC Press.

Ergen, E.; Akinci, B. 2008. Formalization of the flow of component-related information in precast concrete supply chains, Journal of Construction Engineering and Management 134(2): 112-121. https://doi.org/10.1061/(ASCE)07339364(2008)134:2(112)

Ergen, E.; Akinci, B.; Sacks, R. 2007. Life-cycle data management of engineered-to-order components using radio frequency identification, Advanced Engineering Informatics 21(4): 356-366. https://doi.org/10.1016/j.aei.2006.09.004

Furlani, K. M.; Pfeffer, L. E. 2000. Automated tracking of structural steel members at the construction site, in International Symposium on Automation and Robotics in Construction, 18-20 September 2000, Taipei, Taiwan.

Hiremath, H.; Skibniewski, M. J. 2004. Object-oriented modeling of construction processes by unified modeling language, Automation in Construction 13(4): 447-468. https://doi.org/10.1016/j.autcon.2003.09.011

Hruby, P. 1998a. Specification of workflow management systems with UML, in OOPSLA-98 Business Object Workshop, 18-22 October 1998, Vancouver, Canada.

Hruby, P. 1998b. Structuring specification of business systems with UML, in OOPSLA-98 Business Object Workshop, 18-22 October 1998, Vancouver, Canada.

Jang, W.; Skibniewski, M. J. 2008. A wireless network system for automated tracking of construction materials on project sites, Journal of Civil Engineering and Management 14(1): 11-19.

https://doi.org/10.3846/1392-3730.2008.14.11-19

Jiang, S.; Jang, W.; Skibniewski, M. J. 2012. Selection of wireless technology for tracking construction materials using a fuzzy decision model, Journal of Civil Engineering and Management 18(1): 43-59.

https://doi.org/10.3846/13923730.2011.652157
Joosten, S. 1994. Trigger modeling for workflow analysis, in $9^{\text {th }}$ Austrian-informatics Conference on Workflow Management, Vienna, Hagenberg, Austria.

Koskela, L. 1992. Application of the new production philosophy to construction. Technical Report No. 72, CIFE Department of Civil Engineering, Stanford University.

Koskela, L.; Howell, G.; Ballard, G.; Tommelein, I. 2002. The foundations of lean construction, in Design and construction: Building in value. Butterworth-Heinemann, Elsevier, Oxford, UK. Chapter 14.

Lin, Y.; Tserng, H. 2001. A model of supply chain management for construction using information technology, in $18^{\text {th }}$ Symposium of Automation and Robotics in Construction, 10-12 September 2001, Krakow, Poland.

Lipman, R. 2009. Details of the mapping between the CIS/2 and IFC product data models for structural steel, Journal of Information Technology in Construction 14(1): 1-13.

Medina-mora, R.; Winograd T.; Flores, R. 1992. The action workflow approach to workflow management technology, in ACM Conference on Computer-Supported Cooperative Work, 1-4 November 1992, Toronto, Canada.

Naim, M.; Naylor, J.; Barlow, J. 1999. Developing lean and agile supply chains in the UK house building industry, in $7^{\text {th }}$ Annual Lean Construction Conference, 26-28 July 1999, California, USA.

O’Brien, W. J.; London, K.; Vrijhoef, R. 2002. Construction supply chain modeling: a research review and interdisciplinary research agenda, in $10^{\text {th }}$ Annual Conference on Lean Construction, 6-8 August 2002, Gramado, Brazil.

Omar, B.; Ballal, T. 2009. Intelligent wireless web services: context-aware computing in construction-logistics supply chain, Journal of Information Technology in Construction 14: $289-308$.

Opdenakker, R. 2006. Advantages and disadvantages of four interview techniques in qualitative research, Qualitative Social Research 7(4): 1-11.

Park, J.; Cho, Y.; Ahn, C. 2016. A wireless tracking system integrated with BIM for indoor construction applications, in Construction Research Congress, 31 May - 2 June 2016, San Juan, Puerto Rico. https://doi.org/10.1061/9780784479827.265

Pestana, A.; Alves, T.; Barbosa, A. 2014. Application of Lean construction concepts to manage the submittal process in AEC projects, Journal of Management in Engineering 30(4). https://doi.org/10.1061/(ASCE)ME.1943-5479.0000215

Rolland, C.; Pernici C. T. 1998. A comprehensive view of process engineering, in $10^{\text {th }}$ International Conference CAiSE'98, 8-12 June 1998, Pisa, Italy. https://doi.org/10.1007/bfb0054216

Sacks, R.; Eastman, C. M.; Lee, G. 2002. Information and process flow in models of precast concrete design and construction, in $3^{\text {rd }}$ International Conference on Concurrent Engineering, 1-3 July 2002, Berkeley, USA.

Sadiq, W.; Orlowska, M. 1999. On capturing process requirements of workflow based business information system, in $3^{\text {rd }}$ International Conference on Business Information Systems, 14-16 April 1999, Poznan, Poland. https://doi.org/10.1007/978-1-4471-0875-7 23

Schumann, M.; Michael, J. B. 2009. Statechart based formal modeling of workflow processes, in International Conference on System of Systems Engineering, 30 May - 3 June 2009, New Mexico, USA.

Shin, T.; Chin, S.; Yoon, S.; Kwon, S. 2011. A service-oriented integrated information framework for RFID/WSN-based intelligent construction supply chain management, Automation in Construction 20(6): 706-715. https://doi.org/10.1016/j.autcon.2010.12.002 
Tommelein, I. D. 2015. Journey toward Lean construction: Pursuing a paradigm shift in the AEC industry, Journal of Construction Engineering and Management 141(6). https://doi.org/10.1061/(ASCE)CO.1943-7862.0000926

Tommelein, I. D.; Weissenberger, M. 1999. More Just-In-Time: location of buffers in structural steel supply and construction processes, in $7^{\text {th }}$ Annual Conference of the International Group for Lean Construction, 26-28 July 1999, Berkeley, USA.

Trætteberg, H. 1999. Modeling work: workflow and task modeling, in Computer Aided Design of User Interfaces II, 21-23 October 1999, Louvain-la-Neuve, Belgium.

Vrijhoef, R.; Koskela, L. 1999. Roles of supply chain management in construction, in $7^{\text {th }}$ Annual Conference of the International Group for Lean Construction, 26-28 July 1999, Berkeley, USA.

Wang, L.; Lin, Y.; Lin, P. 2007. Dynamic mobile RFID-based supply chain control and management system in construction, Advanced Engineering Informatics 21(4): 377-390. https://doi.org/10.1016/j.aei.2006.09.003
Wang, Y.; Riley, D. 2016. Lean approach to production planning for large solar photovoltaic installations, in Construction Research Congress, 31 May - 2 June 2016, San Juan, Puerto Rico. https://doi.org/10.1061/9780784479827.207

Wegelius-Lehtonen, T.; Pahkala, S. 1998. Developing material delivery processes in cooperation: an application example of the construction industry, International Journal of Production Economics 56-57: 689-698. https://doi.org/10.1016/S0925-5273(98)00077-2

Wirtz, G.; Weske, M.; Giese, H. 2000. Extending UML with workflow modeling capabilities, in $7^{\text {th }}$ CoopIS, 6-8 September 2000, Eilat, Israel.

Yin, S. Y.; Tserng, H. P.; Toong, S. N.; Ngo, T. L. 2014. An improved approach to the subcontracting procurement process in a lean construction setting, Journal of Civil Engineering and Management 20(3): 389-403. https://doi.org/10.3846/13923730.2013.801900

Zheng, H.; Tong, J.; Sun, G. 2015. Modelling a construction materials supply chain for a construction project under VMI, in $5^{\text {th }}$ International Conference on Transportation Engineering, 26-27 September 2015, Dalian, China.

Emre Caner AKCAY. Dr Emre Caner Akcay is currently postdoctoral visiting researcher and part-time instructor of Civil, Architectural and Environmental Engineering at Illinois Institute of Technology. Prior to joining IIT, Dr Emre Caner Akcay was a part-time instructor at Middle East Technical University. He received his PhD, MS and BS degrees in 2014, 2010 and 2008 at Middle East Technical University. His research interests include sustainability, information technologies in construction, project planning and design, contracting and project delivery systems.

Semiha ERGAN. Dr Semiha Ergan is a faculty at NYU Tandon School of Engineering, Department of Civil and Urban Engineering with a courtesy appointment at NYU Department of Computer Science and Engineering. Dr Semiha Ergan is also an associated faculty member at Center for Urban Science and Progress (CUSP). Prior to joining NYU, Dr Semiha Ergan was a research faculty at Carnegie Mellon University. She received her PhD at Carnegie Mellon University in 2008, MS and BS degrees in 2003 and 2000 at Middle East Technical University. Her research interests include IT to support design,construction and operations of civil infrastructure systems, studying urban challenges for AEC/FM, building informatics for efficienct and healthier buildings, quantification of human experience in the built environment, infrastructure information modeling and visualization, and understanding interactions between buildings and city performance.

David ARDITI. Dr David Arditi is currently Professor of Civil and Architectural Engineering at Illinois Institute of Technology. $\mathrm{He}$ is the founder and Director of the Construction Engineering and Management Program. Professor Arditi's area of expertise covers all aspects of construction project management, engineering and support. In his 40-year academic career, he conducted several funded research projects sponsored by federal and state agencies. He supervised the research work of a large number of PhD and MS students from diverse countries. Many of his former $\mathrm{PhD}$ students serve as professors in their respective countries, while many of his former MS students occupy respectable positions in industry all over the world. Dr Arditi and his research associates have published over 300 research papers in refereed national and international journals and in peer reviewed conference proceedings. He is currently serving on the editorial board of nine journals in the field of construction project management, and regularly reviews research proposals, papers and books for several research agencies and publishers. Dr Arditi is an active member of several professional societies including CMAA, ASCE, AACE, and PMI. He has served over the years in many international, national and regional committees and was on several organizing committees of national and international conferences. He delivered several invited lectures and keynote lectures at different venues. He is also the recipient of multiple awards, including being elected to the College of Fellows of CMAA in 2013, and being elected Professor of the Year by CAEE students in 2016. 